\title{
Hydrogen Production via a Commercially Ready Inorganic membrane Reactor
}

Semi-Annual Technical Progress Report

Reporting Period: April 01, 2004 to September 30, 2004

Paul K. T. Liu

Project Director

March 8, 2005

PREPARED FOR THE UNITED STATES

DEPARTMENT OF ENERGY

Under Cooperative Agreement

No. DE-FC26-03NT41852

By

MEDIA AND PROCESS TECHNOLOGY, INC.

1155 William Pitt Way

Pittsburgh, PA 15238 


\section{Disclaimer}

This report was prepared as an account of work sponsored by an agency of the United States Government. Neither the United States Government nor any agency thereof, nor any of their employees, makes any warranty, express or implied, or assumes any legal liability or responsibility for the accuracy, completeness, or usefulness of any information, apparatus, product, or process disclosed, or represents that its use would not infringe privately owned rights. Reference herein to any specific commercial product, process, or service by trade name, trademark, manufacturer, or otherwise does not necessarily constitute or imply its endorsement, recommendation, or favoring by the United States Government or any agency thereof. The views and opinions of authors expressed herein do not necessarily state or reflect those of the United States Government or any agency thereof. 


\section{$\underline{\text { Abstract }}$}

During the $2^{\text {nd }}$ half of Year I, we continued the development of the microporous ceramic layer as a transition layer for the deposition of the carbon molecular sieve membrane on the stainless steel substrate offered by Pall Corp. Based upon the positive result from the feasibility study conducted in the $1^{\text {st }}$ half of Year I, our activities in this period focused on eliminating the high pore size peak and the minimization of defect. A microporous ceramic layer with $40 \mathrm{~A}$ pore size and $<1 \%$ initial flow have been successfully prepared. Further, this modified membrane has demonstrated excellent thermal stability, $<1 \%$ initial flow after the 5 thermal cycles. In addition we began the CMS layer deposition on the AccuSep with the ceramic transition layer. The CMS membranes fired at the low temperature range demonstrate an excellent hydrogen permeance, up to $>5 \mathrm{~m}^{3} / \mathrm{m}^{2} / \mathrm{hr} / \mathrm{bar}$, with the selectivity of $\sim 20$ for $\mathrm{H}_{2} / \mathrm{N}_{2}$. The extremely high permeance is indicative of the extremely thin CMS membrane layer, which becomes possible as a result of the uniform and defect free transition layer. This could be an ideal membrane for hydrogen recovery applications where the hydrogen permeance is the primary concern. Presently we are actively pursuing the intermediate temperature firing to enhance the selectivity to above this range without sacrificing too much permeance. 


\section{TABLE OF CONTENTS}

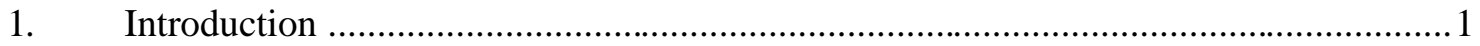

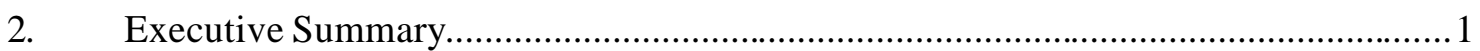

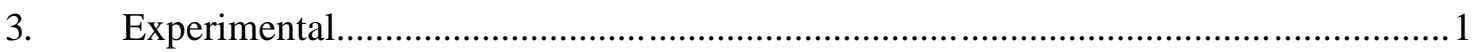

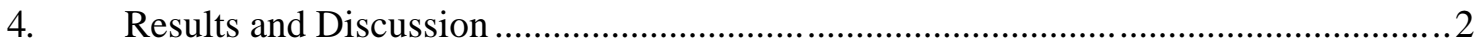

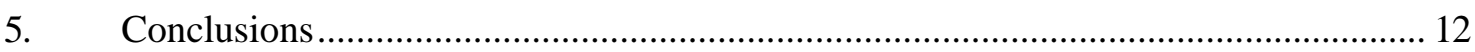

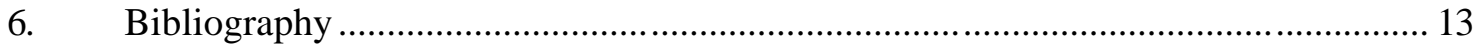

7. Acronyms 


\section{List of Graphical Materials}

Figures

Figure 1 Characterization of Proposed Transition layer on Porous Stainless Steel Substrate (AccuSep from Pall).

Figure 1a Pore Size Distribution of the Ceramic Transition Layer on a Pall AccuSep SS Substrate 4

Figure 1b SEM Micrograph of Proposed Transition layer...................................................5

Figure 1c SEM Photomicrograph of Top Surface of Transition layer at 10KX .....................5

Figure 2 Characterization of Transition layer/SS Substrate after Thermal Cycling: 5

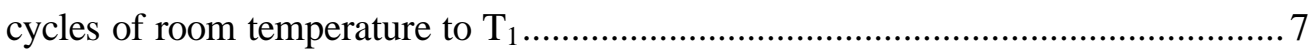

Figure 2a Pore Size Distribution Analysis before and after thermal cycling study ................. 7

Figure $2 \mathrm{~b}$ Percentage initial flow (defect flow, \%IF) measurement following thermal cycling study of the SS substrate coated with the transition layer

\section{$\underline{\text { List of Graphical Materials }}$}

\section{Tables}

Table 1 Permeance of GREEN pre-pyrolyzed membranes prepared on Pall substrates (40A on $\mathrm{ZrO}_{2} .02$ style).. 10

Table 2 Performance of PYROLYZED CMS membranes prepared at low temperature on Pall substrates $\left(40 \AA\right.$ on $\mathrm{ZrO}_{2} .02$ style). 


\section{Introduction}

During this period, we have concentrated on the activities below:

- Optimizing the ceramic transition layer on the stainless steel substrate. Our goal is to minimize the defects and reduce the contribution from the pore size in the range of 100 to 200A range, which was reported in our previous study.

- Verifying the thermal stability of the ceramic transition layer on the stainless steel substrate. Due to the thermal mismatch between the stainless steel and the aluminum oxide, an extremely thin layer is a must in order to tolerate the thermal mismatch.

- Depositing the CMS membrane on the modified stainless steel substrate with the transition layer. Thus, an extremely thin and relatively defect free CMS layer can be prepared, which can deliver a high permeance to overcome the direct deposition of the CMS layer on the stainless steel substrate.

This semi-annual report summarizes the technical results we have obtained during this period.

\section{Executive Summary}

Based upon the positive result from the feasibility study conducted in the $1^{\text {st }}$ half of Year I, our activities in this period focused on eliminating the high pore size peak and the minimization of defect. A microporous ceramic layer with 40 A pore size and $<1 \%$ initial flow have been successfully prepared. Further, this modified membrane has demonstrated excellent thermal stability, $<1 \%$ initial flow after the 5 thermal cycles. In addition we began the CMS layer deposition on the AccuSep with the ceramic transition layer. The CMS membranes fired at the low temperature range demonstrate an excellent hydrogen permeance, up to $>5 \mathrm{~m}^{3} / \mathrm{m}^{2} / \mathrm{hr} / \mathrm{bar}$, with the selectivity of $\sim 20$ for $\mathrm{H}_{2} / \mathrm{N}_{2}$. The extremely high permeance is indicative of the extremely thin CMS membrane layer, which becomes possible as a result of the uniform and defect free transition layer. This could be an ideal membrane for hydrogen recovery applications where the hydrogen permeance is the primary concern. Presently we are actively pursuing the intermediate temperature firing to enhance the selectivity to above this range without sacrificing too much permeance.

\section{Experimental}

Experimental methods employed during this period include:

3.1. Deposition of Microporous Ceramic Membrane as a Transition Layer

\section{- $\quad$ Synthesis of Ceramic Transition Layer...}

Our previous study shows the feasibility of forming a ceramic transition layer composed 
i.e., 4 to $50 \mathrm{~nm}$ pore size $\mathrm{AbO}_{3}$ sublayer ( 1 to $10 \mu \mathrm{m}$ thickness depending upon the pore size). During this period we refined our existing deposition formula and methodology to prepare test quantity of samples. Our refinement focused on the optimization of the layer thickness to minimize defects.

\section{- $\quad$ Characterization of Ceramic Transition layer...}

The stainless steel substrate deposited with the ceramic transition layer was characterized as follows: (i) layer thickness, layer adhesion, and surface topography via SEM photomicrograph, (ii) defect measurements via initial flow or pore condensation methods (for defects defined as pore size $>25 \mathrm{~nm}$ ), and (iii) pore size distribution analyses via the flow-through pore condensation porometry (for pore size between 2 to $20 \mathrm{~nm}$ ) [16]. Thermal stabilities was also performed. The testing conditions are between room temperature and a selected low temperature range, $\mathrm{T}_{1}$, for thermal cycling. In our preliminary study, we performed 5 thermal cycles without introducing defects/cracks/delamination of the transition layer as presented in Sec. 4.2. The characterization method adopted above was employed here to perform comprehensive characterization of the transition layer.

\section{2. $\quad$ CMS Membranes Produced via Pyrolysis at Low Temperature}

Screening study was employed to identify a membrane with an optimized pore size. Several different types of membranes were prepared by controlling the firing temperature. Parts to be considered for the low temperature firing are the Pall-62, $x 4$, and 208. Tables 1 and 2 show the membrane permeances of the green pre-pyrolyzed and finished pyrolyzed membranes, respectively. Membranes were prepared on $\mathrm{Pall}_{\mathrm{ZrO}} \mathrm{Zr}_{2}-02$ style substrates with M\&P microporous layer coating.

\section{Results and Discussions}

\subsection{Surface Characterization of The Transistion Ceramic Layer}

The surface of the diffusion layer was characterized by SEM and pore size distribution analysis. Figure 1a presents the pore size distribution of this layer, resulting in an average $4 \mathrm{~nm}(40 \AA$ ) pore size. Negligible flow by defects (i.e, flow contribution from pores $>20 \mathrm{~nm}$ ) indicates that the transition layer is nearly defect free. For comparison, the pore size distribution of the mesoporous $\mathrm{Ab}_{2} \mathrm{O}_{3}$ sublayer deposited on the commercial $\mathrm{Ab}_{2} \mathrm{O}_{3}$ substrate is shown in the same figure. An SEM photomicrograph of the cross section of the transition layer and its SS support is illustrated in Figure 1b. The thickness of the $\mathrm{Al}_{2} \mathrm{O}_{3}$ sublayer is in the range of $3 \mu \mathrm{m}$, which was deposited on the $\sim 0.1 \mu \mathrm{m}$ pore size of the $\mathrm{ZrO}_{2}$ sublayer with up to $50 \mu \mathrm{m}$ penetration. Pore sizes $>4 \mathrm{~nm}$ (up to $50 \mathrm{~nm}$ ) of the $\mathrm{Al}_{2} \mathrm{O}_{3}$ sublayer can be obtained by calcination of the transion layer at higher temperatures as practiced routinely in the manufacturing of our commercial ceramic membranes. A uniform and smooth top surface was observed under an extremely high magnification (see Figure 1c). In summary, the characterization results support our claim that a thin, 
defect free, and uniform transition layer has been formed on the SS substrate, which meets the criteria for an ideal transition layer. 


\section{Figure 1 Characterization of Proposed Transition layer on Porous Stainless Steel Substrate (AccuSep from Pall)}

a. Pore Size Distribution of the Ceramic Transition Layer on a Pall AccuSep SS Substrate.

Pore size distribution of the proposed transition layer. The pore size distribution is narrow and well defined, similar to our commercial ceramic membrane prepared with a similar $\mathrm{Ab}_{2} \mathrm{O}_{3}$ sol. The average pore size of this transition layer is $\sim 4 \mathrm{~nm}$. The pore size can be altered within the range of 4 to $50 \mathrm{~nm}$ depending upon the firing temperature.

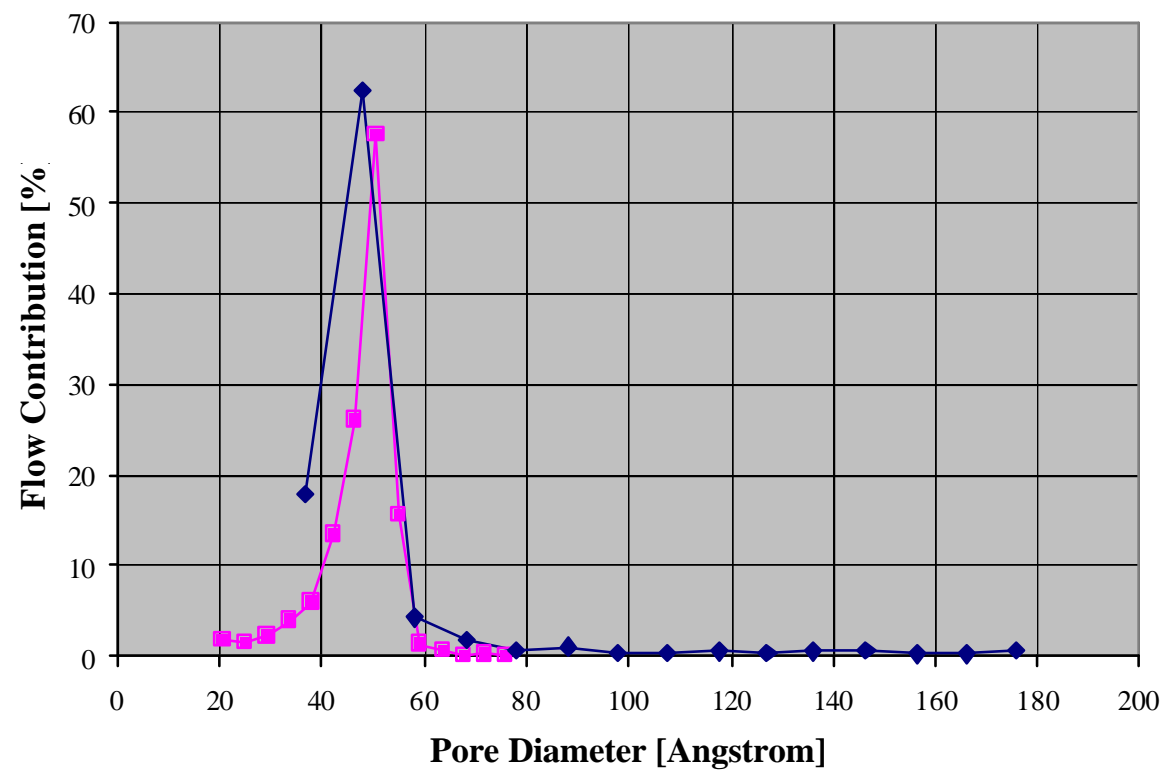

M\&P 40A on Ceramic Substrate $\multimap$ M\&P 40A on Pall Accusep Substrate 
b. SEM Micrograph of Proposed Transition layer.

Up to $50 \mu \mathrm{m}$ penetration of the $\mathrm{ZrO}_{2}$ transition layer sublayer was observed (AccuSep Substrate) and $\sim 2-3 \mu \mathrm{m}$ thick $\mathrm{Al}_{2} \mathrm{O}_{3}$ transition layer was deposited thereon.

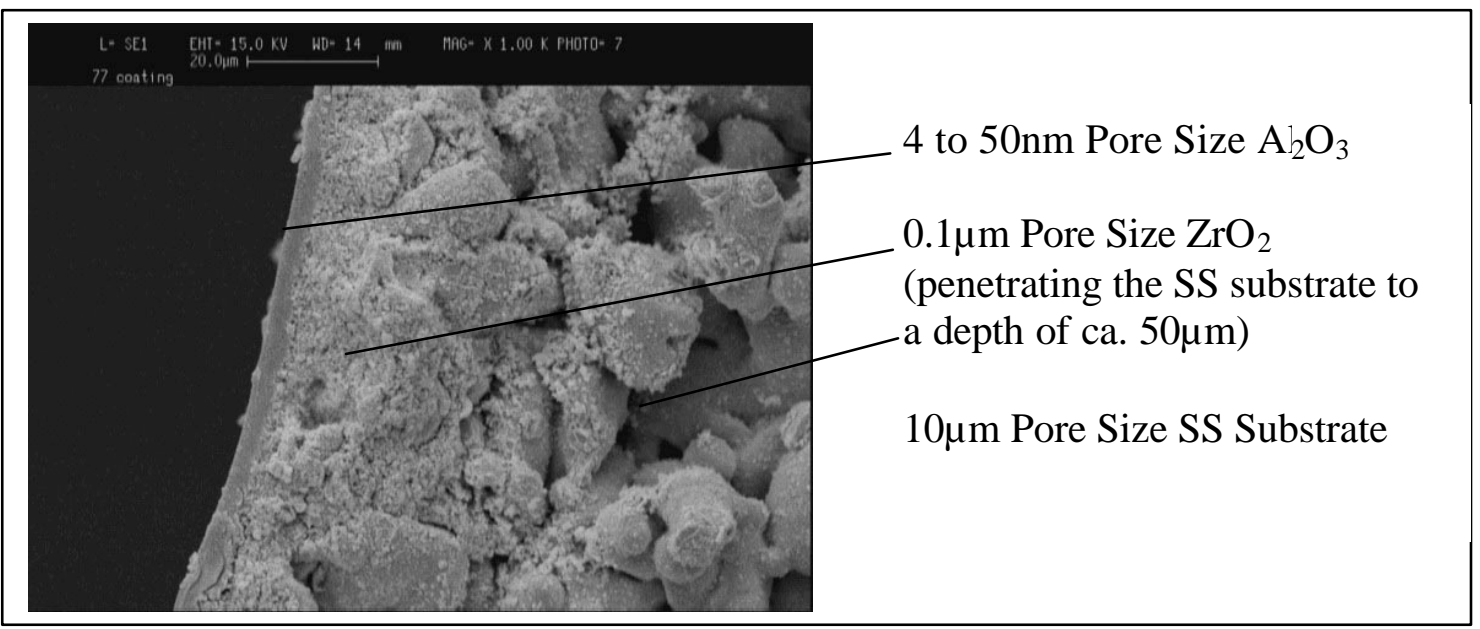

c. SEM Photomicrograph of Top Surface of Transition layer at 10KX

The smooth, defect free $\mathrm{Ab}_{2} \mathrm{O}_{3}$ layer on the inner surface of the tubular SS substrate is observed here, which is conducive to the deposition of an ultrathin Pd layer.

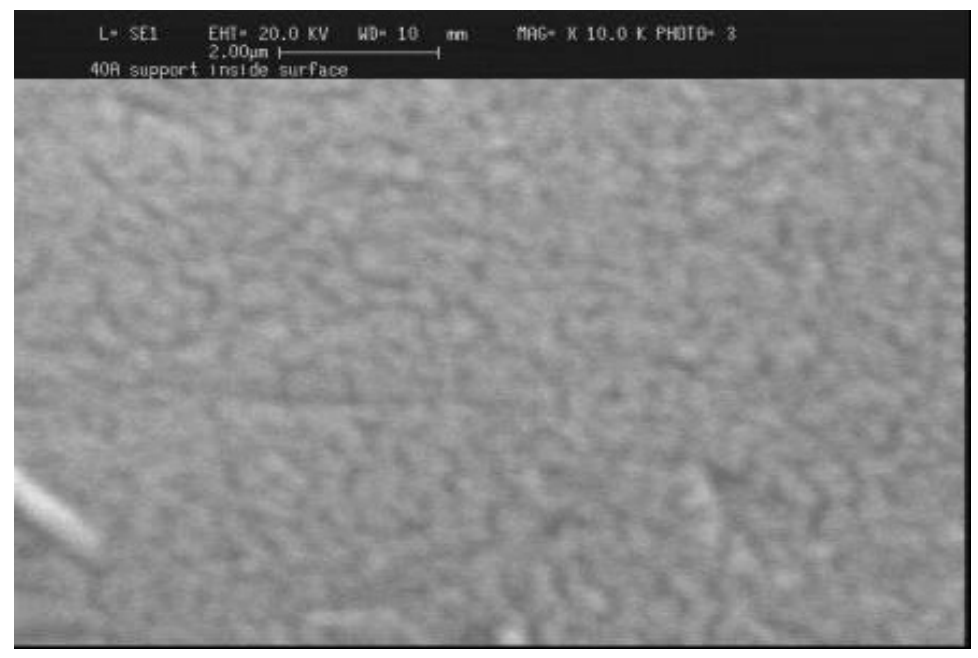




\subsection{Thermal Cycling Study}

A preliminary evaluation was performed to determine whether the transition layer as proposed here could absorb thermal mismatch and remain intact through a large number of thermal cycles (room temperature to $\mathrm{T}_{1}$ ). The initial flow (a QC test method used in our manufacturing) is used here to quantify the defect of the membrane, determined by the ratio of the nitrogen flux of the membrane at $90 \%$ and $0 \%$ relative humidity (water vapor) at room temperature. At $90 \%$ humidity gas, all pores less than about $20 \mathrm{~nm}$ will condense water and hence be plugged and unavailable for $\mathrm{N}_{2}$ flow. The initial flow represents the percentage contribution of the flow from pores (larger than $\sim 20 \mathrm{~nm}$ ), which in this work are considered defects. By this definition, the percentage initial flow (\%IF) of our commercial $4 \mathrm{~nm} \mathrm{Ab}_{2} \mathrm{O}_{3}$ ceramic membranes under this test condition usually falls within 0 to $0.3 \%$ as defined here.

The effect of thermal cycling on the \%IF and pore size distribution of a $4 \mathrm{~nm}$ pore size transition layer prepared by us on the $\mathrm{ZrO}_{2} / \mathrm{SS}$ substrate is shown in Figure $2 \mathrm{~b}$. The $\% \mathrm{IF}$ is stable and extremely low (i.e. $<<1 \%$ ) over 5 thermal cycles, which implies that, no growth in defects occurs as a result. The pore size distribution of the transition layer after the 5 thermal cycles shows no observable change in comparison with that before the test (see Figure 2a). Again negligible defect flow contribution (i.e., > 20nm) was observed. In conclusion, our proposed transition layer was able to absorb the thermal mismatch and kept its microstructure intact. No layer delamination or surface layer crack occurred as evidenced by the initial flow characterization and pore size distribution analysis. (i) The

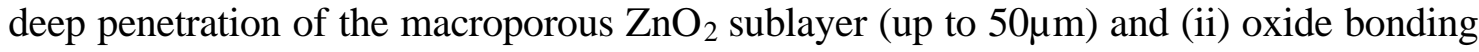
between the two ceramic sublayers are most likely responsible for the physical stability of the transition layer throughout the thermal cycles. 
Figure 2 Characterization of Transition layer/SS Substrate after Thermal Cycling: 5 cycles of room temperature to $T_{1}$

a. Pore Size Distribution Analysis before and after thermal cycling study

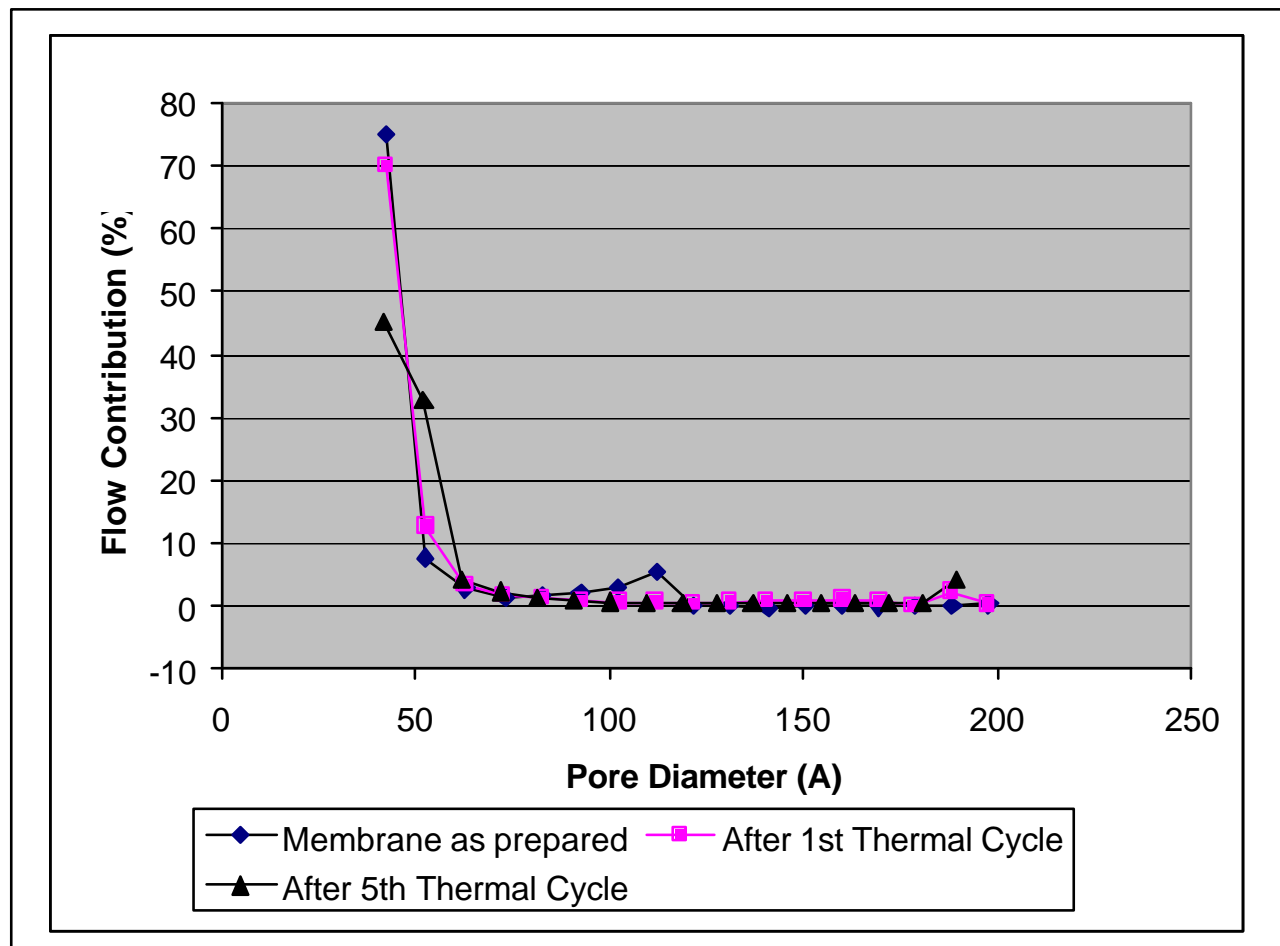

b. Percentage initial flow (defect flow, \%IF) measurement following thermal cycling study of the SS substrate coated with the transition layer (i.e., $40 \AA$ mesoporous $\mathrm{Al}_{2} \mathrm{O}_{3}$ sublayer+ macroporous $\mathrm{ZrO}_{2}$ sublayer). The initial flow is used here to quantify the defects in the membrane top $40 \AA$ layer. The stable and extremely low \%IF following a number of thermal cycles in air implies no microporous structure changes due to thermal cycling.

\begin{tabular}{|l|r|}
\hline Sample ID: Pall 6-28-04 & \% IF(\% of helium flow) \\
\hline Fresh & 0.441 \\
\hline 1 Cycle & 0.299 \\
\hline 2 Cycle & $3.88(?)$ \\
\hline 3 Cycle & 0.454 \\
\hline 4 Cycle & 0.241 \\
\hline 5 Cycle & 0.221 \\
\hline
\end{tabular}




\section{3. $\quad$ Performance Characterization of Low Temperature Firing Products}

In general, during the previous reporting period we showed in a series of CMS membranes prepared using our low temperature firing schedule that relatively defect free membranes could be prepared. These membranes showed little tendency to develop defects in the "crimp" region of the endseal nor delamination of the CMS membrane layer. During the current reporting period we have prepared several additional membranes (DZp-62, DZp-x4) and continued testing a third membrane (DZp-208) that was originally prepared during the previous reporting period. Our primary objective was to verify reproducibility and consider the high temperature performance of these membranes. Table 1 and 2 summarize the permeance results with the green and pyrolyzed membranes (those prepared this reporting period are highlighted in bold-face) and compares the results with membranes prepared during the previous reporting period. Several general results can be discussed.

First, based upon bubble testing of the membrane elements, there appears to be little or no flaws in the endseal following pyrolysis under our low temperature conditions. This is consistent with results from the previous reporting period.

Second, what is clear from the permeance data is that all of the gas permeances are increasing with temperature in the range of RT to $120^{\circ} \mathrm{C}$. This includes the "slow" gases of $\mathrm{N}_{2}$ and $\mathrm{CH}_{4}$ (see parts DZp-208 and 62 in Table 2) and the result is indicative of activated diffusion of these gases. Further, the selectivity of $\mathrm{H}_{2}$ /"slow gases" is relatively low at ca. 10 to 20. Further, the $\mathrm{CH}_{4}$ permeance is comparable to that of $\mathrm{N}_{2}$. B oth of these results are indicative of activated diffusion of the "slow gases" and suggest that the pores are slightly too large to achieve high $\mathrm{H}_{2}$ selectivity. Finally, pores that are simply too large is also consistent with the high $\mathrm{CO}_{2}$ permeance of these membranes. In comparison, CMS membranes prepared by us at much higher pyrolysis temperatures typically display

(i) selectivities of $\mathrm{H}_{2} / \mathrm{N}_{2}>50$ to 100 ,

(ii) slow gas permeances decreasing with temperature in this temperature range, a phenomenon cons istent with very small highly selective pores (minimal $\mathrm{N}_{2}$ permeance) and some minor larger sized membrane defects (Knudsen flow type),

(iii) $\mathrm{N}_{2} / \mathrm{CH}_{4}$ selectivities of 2 to 3 , which again is indicative of highly selective small pore size membranes that can effectively separate gases on the basis of molecular size.

Overall, our results at our low pyrolysis temperature consistently suggest that we can prepare membranes with little or no defects in the endseal region or on the surface of the membrane. These membranes typically show moderate $\mathrm{H}_{2}$ selectivity. However, this temperature is too low to generate highly dense small pore size membranes, a prerequisite for the production of membranes with high selectivity to hydrogen. 
Next Step: During the upcoming reporting period, we will continue to deposit membrane layers on these current parts and pyrolyze at this temperature. Preliminary tests with the DZp-120 membrane prepared during the previous reporting period suggests that additional layers continue to improve membrane performance. However, this part also began displaying leaks in the endseal which complicated the results analysis. 
Table 1. Permeance of GREEN pre-pyrolyzed membranes prepared on Pall substrates (40A on $\mathrm{ZrO}_{2} .02$ style).

\begin{tabular}{|c|c|c|c|}
\hline \multirow[t]{2}{*}{$\begin{array}{l}\text { Membrane } \\
\text { ID }\end{array}$} & \multicolumn{3}{|c|}{$\begin{array}{l}\text { Green Membrane Permeance (Low Temperature Membranes) } \\
{\left[\mathrm{m}^{3} / \mathrm{m}^{2} / \mathrm{hr} / \mathrm{bar}\right]}\end{array}$} \\
\hline & $\begin{array}{c}\mathrm{He} \\
(2.6 \AA)\end{array}$ & $\begin{array}{c}\mathbf{N}_{2} \\
(3.64 \AA)\end{array}$ & Comments on Bubble T est ( $1^{\text {st }}$ Coat Only) \\
\hline \multicolumn{4}{|c|}{ CMS Membrane, $1^{\text {st }}$ Layer Green } \\
\hline DZp-18(1) & 0.0144 & 0.0054 & Several small streamers on one crimp right next to the steel endseal. \\
\hline DZp-120(1) & 0.0433 & 0.0187 & Several small streamers on one crimp right next to steel endseal ( 1 in $1 / 2 "$ interface region) \\
\hline DZp-208(1) & 0.0834 & 0.0353 & Moderate set of streamers in the $1 / 2$ " crimp region one end. Several much smaller at other end \\
\hline DZp-93(1) & 0.243 & 0.113 & Moderate streamers at interface between the steel end and crimp at the "crimp boundary". \\
\hline DZp-x1(1) & 0.269 & 0.130 & Moderate streamers at interface between steel end and crimp. \\
\hline DZp-74(1) & 0.931 & 0.4269 & Fairly large leak one end at the "crimp boundary", small streamer other end. \\
\hline DZp-x3 & 0.27 & 0.13 & \\
\hline DZp-186 & 0.49 & 0.24 & \\
\hline DZp-29 & 1.19 & 0.54 & \\
\hline DZp-x2 & 0.091 & 0.049 & Moderate and smaller leaks in the ends, movie pictures available \\
\hline DZp-26 & 0.692 & 0.375 & Large leak in the center of the element, microscope shows "chips" delaminating \\
\hline DZp-x4 & 0.261 & 0.109 & Crimps look ok with minor leaking (water) \\
\hline DZp-62 & $\mathbf{0 . 9 5 7}$ & 0.416 & Crimps look ok with minor leaking (water) \\
\hline$D Z p-74(1)$ & 0.064 & 0.0258 & Endseals removed and replaced with epoxy. \\
\hline \multicolumn{4}{|c|}{ CMS Membrane, $2^{\text {nd }}$ Layer Green (part has been fired once and recoated with CMS precursor) } \\
\hline DZp-208(2) & Low & Low & \\
\hline DZp-93(2) & 0.0145 & 0.00886 & \\
\hline DZp-120(2) & 0.0017 & Low & \\
\hline DZp-18(1) & 0.0073 & 0.0026 & \\
\hline DZp-x4(2) & 0.055 & $\mathbf{0 . 0 1 1 5}$ & Crimps ok \\
\hline DZp-62(2) & $\mathbf{0 . 0 3 7}$ & 0.0105 & Crimps ok \\
\hline \multicolumn{4}{|c|}{ CMS Membrane, $3^{\text {rd }}$ Layer $/ 3^{\text {rd }}$ Firing on Pall Substrate } \\
\hline DZp-93(3) & Low & Low & \\
\hline DZp-120(3) & Low & Low & \\
\hline DZp-x4(3) & $\mathbf{0 . 0 1 2 7}$ & Low & Crimps ok \\
\hline DZp-62(3) & $\mathbf{0 . 0 0 7 7}$ & Low & Crimps ok \\
\hline
\end{tabular}


Table 2. Performance of PYROLYZED CMS membranes prepared at low temperature on Pall substrates (40Å on $\mathrm{ZrO}_{2} .02$ style).

\begin{tabular}{|c|c|c|c|c|c|c|c|c|}
\hline \multirow{2}{*}{ Membrane ID } & \multicolumn{8}{|c|}{$\begin{array}{l}\text { Pyrolyzed Membrane Permeance (Low Temperature Membranes) } \\
{\left[\mathrm{m}^{3} / \mathrm{m}^{2} / \mathrm{hr} / \mathrm{bar}\right]}\end{array}$} \\
\hline & $\begin{array}{c}\mathbf{H}_{2} \\
(( \\
2.89 \AA\end{array}$ & $\begin{array}{c}\mathrm{He} \\
(2.6 \AA)\end{array}$ & $\begin{array}{c}\mathrm{N}_{2} \\
(3.64 \AA)\end{array}$ & $\begin{array}{c}\mathrm{CH}_{4} \\
(\mathbf{3 . 8 \AA})\end{array}$ & $\begin{array}{c}\mathrm{CO}_{2} \\
(\mathbf{3 . 4 \AA})\end{array}$ & $\begin{array}{l}\text { ethane } \\
(3.9 \AA)\end{array}$ & $\begin{array}{c}\text { propane } \\
(4.3 \AA ̊)\end{array}$ & $\begin{array}{c}\mathrm{i}-\mathrm{C}_{4} \\
(5.0 \AA)\end{array}$ \\
\hline \multicolumn{9}{|c|}{ CMS Membrane on M\&P Ceramic Substrate } \\
\hline DZ-226 & 1.08 & 0.88 & 0.013 & 0.0050 & 0.13 & 0.0015 & NA & 0.0004 \\
\hline \multicolumn{9}{|c|}{ CMS Membrane, $1^{\text {st }}$ Layer $/ 1^{\text {st }}$ Firing on Pall Substrate } \\
\hline DZp-18(1) & & 11.1 & 10.0 & & & & & \\
\hline DZp-93(1) & & 14.2 & 10.3 & & & & & \\
\hline DZp-120(1) & 25.8 & 16.2 & 13.2 & & 29.2 & & 3.46 & \\
\hline DZp-208(1) & & 21.4 & 14.9 & & & & & \\
\hline DZp-x4 & & 6.94 & 5.64 & & & & & \\
\hline DZP-62 & & $\mathbf{1 2 . 2}$ & 9.16 & & & & & \\
\hline \multicolumn{9}{|c|}{ CMS Membrane, $2^{\text {nd }}$ Layer $/ 2^{\text {nd }}$ Firing on Pall Substrate } \\
\hline $\mathrm{DZp}-208(2)$ & 17.5 & 5.18 & 6.29 & NA & 15.1 & 8.9 & 0.76 & 0.0029 \\
\hline DZp-93(2) & 14.9 & 7.6 & 6.6 & & 18.6 & & & \\
\hline DZp-120(2) & 10.4 & 3.5 & 3.1 & & 9.3 & & & \\
\hline DZp-x4 & & 1.14 & 0.52 & & & & & \\
\hline DZP-62 & & 1.46 & 0.588 & & & & & \\
\hline \multicolumn{9}{|c|}{ CMS Membrane, $3^{\text {rd }}$ Layer $/ 3^{\text {rd }}$ Firing on Pall Substrate } \\
\hline DZp-93 & 5.53 & 1.67 & 0.747 & 1.25 & 4.31 & 0.303 & 0.017 & \\
\hline \multicolumn{9}{|c|}{ Bubble test shows only very minor crimp leak. } \\
\hline DZp-120 & 3.87 & 1.23 & 0.63 & 0.73 & 3.48 & & 0.041 & \\
\hline DZp-208 (RT) & 4.21 & & 0.162 & 0.117 & & & & \\
\hline @120C & 5.17 & 2.29 & 0.289 & 0.364 & 2.52 & 0.221 & & \\
\hline \multicolumn{9}{|l|}{ DZp-x4 (RT) } \\
\hline @120C & 1.63 & 0.818 & 0.151 & 0.207 & 0.660 & 0.126 & & \\
\hline DZP-62 (RT) & 1.90 & 0.74 & 0.211 & 0.211 & (RT data & taken afte & 120 data $b$ & low) \\
\hline$@ 120 \mathrm{C}$ & 2.26 & 1.17 & 0.231 & 0.287 & 1.02 & 0.221 & & \\
\hline & & & & & & & & \\
\hline
\end{tabular}




\section{Conclusions}

During the $2^{\text {st }}$ half of Year I, we have concentrated on the development of the ceramic transition layer on the Pall's commercial stainless steel substrate (AccuSep) and began the deposition of M\&P Carbon Molecular Sieve (CMS) hydrogen selective membrane. Several conclusions can be drawn from this period:

- In order to produce a hydrogen selective membrane with an excellent permeance, an extremely thin CMS layer on the stainless steel substrate is essential. To achieve this objective a uniform and defect free microporous ceramic transition layer was suggested. Our results from this period indicate that a unform and defect free microporus layer has been deposited successfully on the stainless steel substrate. The pore size distribution analysis indicates a narrow and well defined distribution with an average pore size of $4 \mathrm{~nm}$. The initial flow analysis (an index for defect) indicates $<1 \%$ contribution by the defect.

- The thermal cycling study demonstrated the integrity of the ceramic transition layer after a total of five cycles. No shift in pore size distribution and no increase in the initial flow are indicative of the physical integrity of this transition layer. We believe that the extremely thin layer of this transition layer tolerates the thermal mismatch between the ceramic and the stainless steel.

- The CMS membrane prepared with this modified substrate at low pyrolysis temperatures shows an extremely high hydrogen permeance, up to $5 \mathrm{~m}^{3} / \mathrm{m}^{2} / \mathrm{hr} / \mathrm{bar}$, with the selectivity of $\sim 20$ for $\mathrm{H}_{2} / \mathrm{N}_{2}$. This high permeance is attributed to the extremely thin carbon molecular sieve layer formed on this improved transition layer. However, higher temperature pyrolysis will be necessary to enhance the selectivity without sacrificing too much permeance. Initial results obtained with stainless steel supported CMS membranes prepared at higher pyrolysis temperatures indicate that defects are appearing in the substrate layer and endseal. This has lead to lower than expected improvements in the membrane selectivity in comparison with parts prepared on ceramic substrates. During the next period, our focus will be on improving membrane quality by eliminating these defects. 


\section{Bibliography}

1. Gallaher, G.R. Liu, P. K. T., "Characterization of ceramic membranes, I. Thermal and hydrothermal stabilities of commercial 40A membranes", J. Memb. Sci, 92, 29(1994), 
$\underline{\text { Acronvms }}$

SEM Scanning Electro microscopic

M\&P Media and Process Technology, Inc.

AccuSep Trade name of Pall's Stainless Steel Membranes

CMS Carbon Mole cular Sieve

$\%$ IF Flow of the Membrane contributed by defects 